\title{
A DISTINCC̃̃O ENTRE PENSAMENTO CALCULADOR E PENSAMENTO MEDITATIVO NA FILOSOFIA TARDIA DE MARTIN HEIDEGGER
}

The distinction between calculating thinking and meditative thinking in Martin Heidegger's late Philosophy

\author{
Ana Carla de Abreu Siqueira ${ }^{1}$ \\ “[...] estou habituada a não considerar perigoso pensar." \\ (Clarice Lispector, in A descoberta do mundo)
}

\begin{abstract}
RESUMO
Este artigo pretende elucidar dois conceitos fundamentais na filosofia tardia de Martin Heidegger: o pensamento calculador e o pensamento meditativo. Em um primeiro momento, apresentamos o pensamento calculador, o qual é bastante comum na época moderna através do domínio do sujeito e da técnica. Em seguida, apresentamos o pensamento meditativo e sua proximidade à questão do ser. A meditação se abstém do controle do mundo e precisa ser cultivada como uma habilidade do ser humano. A distinção entre pensamento calculador e pensamento meditativo diz respeito ao pensamento humano e às ações humanas, como vemos na era atual.
\end{abstract}

Palavras-chave: Martin Heidegger. Pensamento calculador. Pensamento meditativo. Serenidade. Técnica.

\begin{abstract}
This article intends to elucidate two fundamental concepts in Martin Heidegger's late philosophy: the calculating thinking and the meditative thinking. At first, we present the calculating thinking, which is quite significantly in the modern age through the dominance of the subject and the technique. Then, we present the meditative thinking and its proximity to the question of the being. The meditation abstains itself from the control of the world and needs to be cultivated as a human being ability. The distinction between calculating thinking and meditative thinking concerns to human thought and human actions, as we see in the current era.
\end{abstract}

Keywords: Calculating thinking. Martin Heidegger. Meditative thinking. Serenity. Technique.

\footnotetext{
${ }^{1}$ Doutora em Filosofia pela Universidade Federal do Ceará - Fundação Cearense de Apoio ao Desenvolvimento Científico e Tecnológico. Pesquisadora independente.

E-mail: carladeabreus@gmail.com. ORCID: http://orcid.org/0000-0002-3344-2863
} 


\section{Introdução}

Este artigo faz parte de uma pesquisa mais ampla sobre o processo de transformação do pensamento dentro da filosofia heideggeriana. Transformar o pensamento significa sairmos do paradigma do sujeito pensante que fundamenta eventos e fenômenos a fim de buscarmos uma forma de reflexão que integra a existência humana ao mundo, aos outros e ao tempo. Martin Heidegger (1889-1976) jamais negou que homens e mulheres são entes capazes de pensar, mas procurou um novo aparato conceitual para falar sobre esse processo. A relação entre pensamento meditativo e pensamento calculador é parte de um período de reflexões que, após o desenvolvimento da analítica existencial e da hermenêutica da facticidade, envolve a técnica, a poesia e a verdade do ser.

Imaginemos um lavrador em mais um dia de sua rotina: ele acorda ao nascer do sol e então percorre o caminho até o campo, onde inicia o trabalho com seus utensílios. Após cultivar a terra, cumprir as etapas do processo e seguir com cuidado os passos exigidos, ele atravessa o período de espera pelo despontamento e pelo amadurecimento da semente. Finalmente, chega à ocasião da colheita. Conforme Heidegger, o pensamento meditativo (das besinnliche Denken) se assemelha à atividade cotidiana do camponês, a qual exige paciência, entrega e dedicação. Por não surgir espontaneamente ou, conforme a metáfora, por ainda estar no solo da existência, esse pensamento precisa ser cultivado. Meditar é demorar-se no pensamento.

No entanto, a meditação é esquecida quando outro modo de pensar predomina em nossas experiências. Trata-se do pensamento calculador (das rechnende Denken), o qual "corre de oportunidade em oportunidade" (HEIDEGGER, 2002b, p.13). Com esse modo de pensar, somos guiados por cálculos e métodos específicos que exigem resultados concretos, porém, sem nos conectarmos intimamente aos meios reflexivos de atingir cada um. Essa relação ainda tem recebido pouca atenção nos estudos brasileiros, pelo menos em comparação a outros temas mais comuns ao percurso heideggeriano, tais como a origem da obra de arte, a ontologia fundamental e a poesia. Por essa razão, o objetivo deste texto é mostrar como Heidegger explorou os dois conceitos e apontar a sua importância na sua obra. Compreender esses 
modos de pensamento humano certamente possibilita nos apropriarmos de suas ideias para as vivências e situações atuais.

\section{O cálculo e o pensamento calculador}

A noção de cálculo (das Rechnen) emergiu na modernidade com o desenvolvimento das ciências modernas e é basilar para a compreensão de como Heidegger explica as tarefas do pensamento. Com isso, tornou-se algo muito comum dominar os entes manipulados nos processos científicos e até mesmo nas tarefas cotidianas. A principal consequência é ter modificado substancialmente as formas de acesso aos entes, transformando-os em objetos programados e calculáveis. Mas todos os processos realizados na era da técnica são unilateralmente ordenadores devido à tentativa humana de assegurar resultados específicos e previsíveis, por meio de métodos capazes de medir, transformar e manipular a realidade. A definição que Heidegger atribui ao cálculo coincide com a essência do trabalho científico:

O cálculo é o procedimento assegurador e processador de teoria do real. Não se deve, porém, entender cálculo em sentido restrito de se operar com números. Em sentido essencial e amplo, calcular significa contar com alguma coisa, ou seja, levá-la em consideração e observá-la, ter expectativas, esperar dela alguma outra coisa. (HEIDEGGER, 2006, pp.49-50)

Com a exposição acima, podemos esboçar algumas ações próprias ao comportamento orientado pelo cálculo: assegurar, medir, processar, quantificar, dominar, ordenar, contar com, considerar, tornar objeto, observar, determinar, esperar $d e$. Todo ente revela alguma utilidade na proporção em que ele pode ser enumerado, posto em categorias (HEIDEGGER, 2008b, p.321). $\mathrm{Na}$ verdade, a postura calculadora está presente em todos os nossos passos de forma tão crescente, que não conseguimos suspender inteiramente o cálculo neste mundo elaborado que permite tantas descobertas.

Quem leu o prólogo de A condição humana, obra fundamental de Hannah Arendt para a filosofia contemporânea, entende o porquê de todas as conquistas do modo de pensar calculador se mostrarem insuficientes no que diz respeito às nossas experiências de pensamento. Nós certamente nos adaptamos aos avanços científicos e técnicos, porém, a vida humana é es- 
sencialmente modificada a ponto de arriscar destruir a si mesma e, por isso, ela propõe que possamos "refletir sobre o que estamos fazendo." (ARENDT, 2008, p.13) Sem entrarmos na importância da questão política trazida pela filósofa, o que apontamos aqui é o entendimento de que, se nossa verdadeira emancipação depender apenas da esfera calculadora, de fórmulas e da tecnologia, por exemplo, seremos reduzidos a entes que não dialogam sobre a própria condição ou, à luz da filosofia heideggeriana, deixamos de pensar um sentido para nosso ser.

Por um lado, existe uma explicação positiva acerca da presença do cálculo na vida cotidiana: uma vez que tudo o que é calculado se transforma em algo com o que se pode contar, é por meio do cálculo que reunimos os entes a partir de regras e projetos que os conferem determinada importância e alguma utilidade, tornando-os cada vez mais acessíveis. Em outras palavras, tal processo ajuda a organizarmos tarefas e trabalharmos melhor em direção às nossas conquistas. Assim como é feito com algum acordo entre seres humanos com a finalidade de melhorar a vida em comunidade ou que simplesmente se reconheçam em um grupo, o cálculo permite ao ser-aí contar com os entes circundantes (HEIDEGGER, 2010b, p.449).

Por outro lado, qual problema surge nessa mudança? Heidegger acredita que o pensamento se modificou bastante a ponto de abandonar qualquer reflexão sobre o sentido do ser. Quando pensamos através do cálculo, tanto a eficácia como os resultados têm mais valor do que o desvelamento da verdade e qualquer cuidado no trato com os entes. Além disso, as teorias criadas a partir desse processo modificam os fenômenos quando estes são enquadrados em alguma região de objetos. O pensamento calculador é um tema essencial para o Heidegger tardio e também diz muito sobre a época na qual vivemos. É um tipo de pensar que não expressa a dimensão ontológica da afetividade ${ }^{2}$; que não mantém a conexão humana com a terra e sua atmosfera de convivência; e que não espera para conhecer a essência de

\footnotetext{
${ }^{2}$ Befindlichkeit é a estrutura existencial que permite ao Dasein ser afetado (HEIDEGGER, 2012, p.393) por eventos que se advêm sobre ele nos aspectos físico e afetivo. É assim que cada um de nós permanece a todo instante em algum estado de ânimo, interessado em algum fenômeno e envolvido com o mundo. $\mathrm{O}$ conceito abriga aquilo que experimentamos no cotidiano como uma forma particular de sentir, chamada de tonalidade afetiva ou humor (Stimmung).
} 
algo, pois sempre espera tomar algo dos entes e da natureza para seu consumo.

Apesar de só ter adquirido uma reflexão madura na conferência $\mathrm{Se}$ renidade, existe em Ser e tempo (1927) uma indicação prévia sobre as consequências da postura calculadora. Através do questionamento sobre como nos comportamos no mundo, Heidegger introduz uma discussão sobre a utilidade dos entes. Ao defender que existimos no mundo e nos compreendemos como entes cujas ocupações fazem parte do nosso modo de existir, o filósofo entende que fazemos isso porque buscamos estabilidade e resultados concretos. É através desse modo trivial de agir que o Dasein "conhece, discute, aprova, combate, retém e esquece, mas sempre de olhos postos primariamente no que se faz e no que daí 'surge'." (HEIDEGGER, 2012, p.1049) Então, o olhar humano se acostuma a priorizar tudo o que é mensurável para realizar novas descobertas ${ }^{3}$.

Até mesmo cobramos uns dos outros que todas as tarefas sejam cumpridas utilizando ao máximo nossas capacidades. Logo, o pensamento calculador é aquele modo de pensar que trabalha com a tentativa humana de dominar a natureza, os entes e a própria existência. Se esse comportamento era típico do homem moderno, a situação permanece semelhante nos dias atuais e arriscamos dizer que continua se aprofundando. Ainda podemos evocar as palavras do filósofo alemão, quando ele afirma, sobre o tempo no qual ele viveu, que "em época alguma se realizaram planos tão avançados, se realizaram tantas pesquisas, se praticaram investigações de forma tão apaixonada" (HEIDEGGER, 2002b, p.13). Heidegger faz suas críticas ao pensamento calculador e se preocupa em reconhecer seus equívocos a fim de apontar um modo de pensar pelo qual possamos ver as coisas de outra forma.

\footnotetext{
${ }^{3}$ É importante ressaltar que em Ser e tempo ainda não é apresentada uma crítica severa à técnica e seus processos. Aí a ênfase está no aspecto positivo da técnica, como Franco Volpi destaca ao dizer que Heidegger se refere a uma "atitude de tomar cuidado, que é antes de tudo um ter que fazer com as coisas no sentido de utilizar-se delas em contextos operativos (Zuhandenheit), e só secundariamente um simples conservá-las na sua presença (Vorhandenheit). Mas a utilização das coisas em contextos operacionais é precisamente a atitude que na técnica moderna é elevada à maior potência e absolutizada na finalidade de padronizar o ente." E o autor prossegue dizendo que o filósofo alemão "interpreta a técnica como um dos modos em que o ser-aí é descobridor; isto é, acede ao ente e se põe em relação com ele." (VOLPI, 2013, pp.147-8)
} 
A característica mais negativa do pensamento calculador é não refletir sobre si mesmo e deixar de fazer perguntas sobre o sentido de pensar, quais suas motivações e seus fundamentos, apesar de procurar cada vez mais deter informações. Essa atitude que nos conduz a descobertas e ao aperfeiçoamento de tudo o que já dispomos é a mesma segundo a qual Heidegger diz que "toma-se conhecimento de tudo pelo caminho mais rápido e mais econômico e, no mesmo instante e com a mesma rapidez, tudo se esquece." (HEIDEGGER, 2002b, p.14) E o que é isto que se esquece? As condições prévias das nossas atitudes, como viver sem um apego exagerado aos objetos técnicos, o sentido do ser e o próprio pensamento, embora a capacidade de pensar jamais nos abandone ${ }^{4}$.

Assim, é muito fácil que o interesse que nutrimos por algo seja logo perdido e se transforme em um acontecimento distante, sem importância e facilmente substituível por novos interesses. De fato, muita coisa é produzida, planificada e interpretada a todo instante. Mas quando o pensamento calculador foi estabelecido como principal condução de nossas reflexões, tomou o lugar de um pensar originário e mais elevado. O método do cálculo trabalha com entes e se esquece de perguntar pelo ser, visto que sua prioridade é cumprir metas guiadas por algum propósito específico e apresentar resultados imediatos.

Isso acontece porque o pensamento que calcula está próximo da Gestell, isto é, a essência da técnica moderna. Ao contrário dos gregos antigos que se colocavam disponíveis à revelação do ser, os modernos pretendiam manipular os entes. Gestell é uma composição que faz o sujeito atuar como um dominador, um sujeito provocado a agir de determinada maneira sem sequer perceber qual poder o conduz e sem questionar quais as condições e consequências de tais ações (BORGES-DUARTE, 2014, p.17). Esse modo de pensar é guiado pela noção de instrumentalidade e provoca toda reserva com a qual a existência se depara, até que se esgotem sua utilidade e sua importância.

Na idade da técnica, o Dasein não é um artesão ou um produtor interessado em desvelar, pois se converte em um técnico que enxerga ocupa-

4 Segundo Heidegger (2002a, p.31): "Se o pensamento é o traço distintivo da essência do homem, então o essencial desta essência, ou seja, a essência do pensamento, só pode ser apercebida desviando o olhar do pensamento". 
ções, objetivos e condições, transformando a si mesmo em reserva. O que marca o desenvolvimento do cálculo e como ele passou a reger o pensamento na era das ciências e da técnica moderna? O momento em que, a partir da representação de suas expectativas, o homem passou a contar com os entes com o propósito de indicar sua utilidade e de elaborar teorias sobre a realidade.

Em Contribuições à filosofia (Do acontecimento apropriador) (1936/38), o filósofo alemão aponta algumas diretrizes em torno da fundamentação do cálculo: este se desenvolve a partir da "maquinação da técnica" (HEIDEGGER, 2015, p.119) e de todo planejamento feito para que os resultados sejam os mesmos propostos pelo projeto inicial. Seria então preciso seguir o caminho escolhido a partir das metas estabelecidas a fim de se assegurar dos entes. Quando há certeza e garantia sobre os entes, realizamos cada vez mais transformações e criamos imagens ${ }^{5}$. Nesse caso, o ser-nomundo deixa de se questionar e meditar sobre um sentido a todo instante, uma vez que ele se orienta pelas determinações do cálculo. Heidegger relaciona o cálculo diretamente a dois fenômenos específicos, a saber, a rapidez e a massificação.

A rapidez expressa toda a velocidade com que a técnica atinge seus objetivos e consiste em um fenômeno que vai contra um modo de pensar que exige calma, espera e dedicação. Por sua vez, massificação é a ampla divulgação de todas as informações e descobertas. Se tudo o que é calculável já é externo ao Dasein, a pretensão é tornar tudo mais acessível ao entendimento de um maior número de seres humanos. O pensamento que calcula promove "a distribuição calculada, rápida e maciça de conhecimentos não compreendidos na maior quantidade possível e no menor tempo possível" (HEIDEGGER, 2015, p.121), tendo como consequência uma ampla e inadequada difusão de informações. Um exemplo atual é a divulgação de fake news em redes sociais, processo que acontece em uma velocidade seis vezes mais rápida do que a divulgação de uma notícia verdadeira.

$\mathrm{O}$ que pretende, afinal, o pensamento que calcula e toda tarefa que utiliza o método calculador para alcançar o conhecimento? Antes de viver com qualquer inquietação, o existente humano quer se assegurar dos entes e

5 Heidegger (2015, p.119) expressa que "nada é impossível, se está certo do "ente"”. 
ter a certeza de que, ao dominá-los, poderá fazer o que quiser com eles. A partir disso, acredita que pode transformar o mundo e a natureza de acordo com suas necessidades e vontades. Mas quando ele pensa sob a influência do cálculo, corre o risco de abandonar as perguntas realmente importantes. Quando tudo é transformado por meio do cálculo, torna-se apenas mais um objeto técnico para uso e conforto humanos. O homem da era atômica, por exemplo, enxergava a ciência como o caminho para o futuro sem sequer refletir sobre o sentido das suas escolhas e sem justificar suas atitudes.

De maneira geral, procuramos resultados práticos, bem-estar e eficiência, além de esperarmos que a natureza esteja disponível como uma fonte inesgotável de recursos na qual investimos tempo e conhecimento. O pensamento calculador transforma terra e mundo em objetos ao olhar para esses elementos com a intenção de dominá-los. Enquanto o mundo deixa de ser aquele campo de acesso ao sentido e se converte no lugar onde o ser-aí realiza seus planos, a terra deixa de ser o abrigo da verdade que se desvela (HEIDEGGER, 2010a, p.105) para se transformar no repositório de onde ele retira recursos para explorar e cumprir suas metas. Logo, é essencial pensarmos além da perspectiva calculadora para trazermos à luz a verdadeira relação que devemos ter com terra e mundo.

A influência do cálculo no pensamento investigativo tem como pano de fundo o esquecimento do ser. Afinal, não se pode calcular o ser, tampouco ordenar ou manipular a manifestação do seu sentido. Só podemos compreender os pressupostos do pensamento calculador quando tomamos consciência da diferença ontológica, distinção que não nos permite falarmos do ente sem a concepção prévia do ser $^{6}$. Em termos mais explicativos, isso quer dizer que jamais impomos a noção de ser, pois perseguimos sua manifestação através de uma abertura, a qual infelizmente está soterrada pelo cálculo e pela técnica. Dessa perspectiva, é bastante apropriada a definição de Marlène Zarader, onde se lê: “O pensamento calculador é o que se afastou

\footnotetext{
${ }^{6} \mathrm{O}$ ser não se define, mas quando usamos a palavra 'ser', já existe o pressuposto de que esse conceito tem uma especificidade que serve para distinguir que as coisas são e se dão para nós. Como afirmou Heidegger: "Ser e estrutura-do-ser residem acima de todo ente e de toda possível determinidade ôntica de um ente. Ser é o transcendens pura e simplesmente." (HEIDEGGER, 2012, p.129)
} 
do seu elemento original. [...] está ordenado de outra maneira e mantém-se na obediência àquilo que não lhe é próprio.” (ZARADER, 1998, p.143).

Pode-se até mesmo dizer que se trata de um comportamento mais interessado em nos colocar em estado constante de avaliação dos entes, acúmulo de informações e interposição de metas do que auxiliar na busca pela verdade do Ser. Para além das transformações que provoca, as quais são bastante relevantes para o desenvolvimento da vida fática, o problema do pensamento é justamente parecer tão espontâneo e, por isso, jamais ser cultivado. Já estamos habituados a uma maneira comum de pensar, moldada pelo pressuposto de que somos sujeitos pensantes. Essa crença indica que devemos depositar na razão todos os nossos interesses e a única via de resolução para os impasses da vida prática ${ }^{7}$. Mas como veremos adiante, o pensamento precisa de um constante esforço de nossa parte e nos conduz na pergunta pelo sentido do ser. Heidegger defende que há outro caminho pelo qual questionamos de forma profunda e cuidadosa o ser de tudo que há.

\section{O pensamento meditativo e o sentido do ser}

O contraponto ao pensamento calculador está no retorno à questão do ser, à noção de que todo modo de pensar necessita de moderação e empenho ao invés de pressa e ânsia por resultados. Heidegger enfatiza o pensamento meditativo e lhe restitui a devida importância perdida na história da filosofia. Para ele, existe uma relação subentendida entre a afetividade e o pensamento que precisa ser trazida à discussão: não precisamos a todo instante atingir uma interpretação do mundo ou alguma justificativa, mas certamente nos devemos manter conectados ao que inspira nossas reflexões. Esse enraizamento é mais decisivo do que toda postura de ordenação e controle excessivos que a técnica insiste em impor.

A história de homens e mulheres é acompanhada pela técnica, mas o pensamento meditativo estagnou diante do desenvolvimento técnico e tecnológico do mundo. Será que ainda há espaço para uma reflexão comedida,

\footnotetext{
${ }^{7}$ Como ressalta Barbara Dalle Pezze (2006, p.98): "Para nós, pensar é uma atividade mental que nos ajuda a resolver problemas, a lidar com situações, a compreender circunstâncias e, de acordo com essa compreensão, agir a fim de seguir em frente. Pensar, para nós, também significa ter uma opinião, ter uma impressão de que algo é de certa forma. Pensar sig nifica raciocínio". Tradução nossa.
} 
sem a pretensão de atingir resultados mais imediatos, palpáveis e que se manifestem na realidade cotidiana? O pensamento meditativo dá conta de nos aproximar dos problemas resultantes de guerras, dos conflitos políticos e religiosos, da relação com a tecnologia e suas novas mídias, dos experimentos científicos? Aliás, ele seria próprio ao homem comum ou seria reservado aos filósofos e poetas, os quais supostamente teriam uma capacidade privilegiada de enxergar o que escapa do horizonte humano de compreensão na rapidez do dia a dia? Na época da conferência Serenidade, quando apresentou o pensamento que medita como a mais alta oportunidade de fugirmos do domínio da técnica e do cálculo, Heidegger enfrentou os mesmos questionamentos.

O texto Serenidade é a transcrição de um discurso proferido no ano de 1955 como homenagem ao compositor Conradin Kreutzer em Meßkirch, sua cidade natal. $\mathrm{O}$ filósofo mostra que a verdadeira homenagem precisa de uma meditação cuidadosa sobre quem estamos trazendo ao centro da discussão; isso é mais importante do que escrever um discurso considerado belo e elogioso pelo efeito das palavras. Ele também reflete sobre a região, o mistério, o espaço e, em especial, a diferença fundamental entre os pensamentos calculador e meditativo. A partir de sua leitura conjunta com o escrito Para discussão da serenidade (de uma conversa sobre o pensamento que teve lugar num caminho de campo), podemos compreender as ideias heideggerianas que descobrem e percorrem um caminho de pensamento no mundo técnico.

Para o filósofo, "qualquer pessoa pode seguir os caminhos da reflexão à sua maneira e dentro dos seus limites." (HEIDEGGER, 2002b, p.14) Com essas palavras, o que ele defende é isto: a partir do entendimento de que cada um é Dasein em seus próprios termos, diz-se que cada um existe no seu modo de ser e, ao mesmo tempo, permanece vinculado aos outros e ao mundo (HEIDEGGER, 2012, p.173). Portanto, o pensar meditativo é um evento que qualquer um poderia alcançar. Heidegger ressalta que essa situação é bastante diferente do cogito cartesiano, por exemplo, quando a subjetividade fora colocada como a forma exclusiva de acesso ao mundo. A meditação é uma atitude reflexiva na qual suspendemos toda busca por um consumismo imediato ou pela necessidade excessiva de novas invenções; 
meditar é um momento onde nos voltamos para o que geralmente é considerado inútil ${ }^{8}$, isto é, tudo o que desaparece diante da praticidade dos entes utensiliares.

Ao procurar pelo ser dos entes, o pensamento meditativo é uma experiência despreocupada com apropriações técnicas. Assim, é fundamental algum esforço para que o Dasein renuncie a uma noção de pensamento que deve sempre produzir efeitos. Fica pressuposto que o filósofo alemão se refere a um fenômeno que devemos conquistar e, por isso, "Requer um treino demorado. Carece de cuidados ainda mais dedicados do que qualquer outro verdadeiro ofício." (HEIDEGGER, 2002b, p.14) Nem sempre qualquer um será capaz de desenvolver a afinidade com uma meditação mais profunda e dissociada da possível eficácia gerada pelo modelo técnico-científico. O pensamento meditativo é aquele que reflete sobre o sentido, que procura uma fundamentação para o ser e pelo qual cada ser-aí está enraizado enquanto ser-no-mundo.

Heidegger evoca a necessidade de nos ligarmos a tudo aquilo com que já deveríamos estar familiarizados, mas que fica encoberto pelas novidades trazidas com o desenvolvimento da técnica e pelo excesso de saberes. Seria antes necessário questionar se o pensar meditativo possibilita a realização de uma práxis e se é capaz de ultrapassar os problemas criados pela maquinação do mundo. No contexto heideggeriano, práxis é uma postura ontológica pela qual, de forma orientada, a existência aplica determinado conhecimento para executar projetos e atingir objetivos (HEIDEGGER, 2010 b, p.444). Porém, para o filósofo alemão há dificuldades mais profundas do que a realização de uma práxis, uma vez que:

[...] aquilo que é verdadeiramente inquietante não é o facto de o mundo se tornar cada vez mais técnico. Muito mais inquietante é o facto de o Homem não estar preparado para esta transformação do mundo, é o facto de nós ainda não conseguirmos, através do pensamento que medita, lidar adequadamente com aquilo que, nesta era, está realmente a emergir. (HEIDEGGER, 2002b, p.21)

O pensamento que calcula é aquele que modifica o mundo, enquanto o pensamento que medita deveria preparar homens e mulheres para o en-

8 Para Heidegger (1995, p.10), “[...] o sentido das coisas é o que se afigura como o mais necessário. Porque se o sentido faltasse, o próprio útil ficaria desprovido de significação e por conseguinte não seria útil." 
frentamento dessas transformações. O problema evidente surgido da concepção calculadora do pensamento é que o homem acredita que todo pensar constitui necessariamente uma ação que demanda alguma produtividade e à qual se seguem efeitos concretos. De certo, pensar realmente é uma ação. Mas é uma ação que está voltada para o sentido do ser, enquanto todas as demais atuações trabalham com a intenção de falar sobre os entes e, em seguida, dominá-los ou criar eventos que satisfaçam a vontade humana. Tal postura é consequência daquilo que Heidegger (2008a, p.327) chama de interpretação técnica do pensamento, onde o pensar está submetido ao fazer e converte a nossa rotina em algo automático, sem questionamentos.

Todavia, seria um engano acreditar que o ser-aí perde um interesse completo quando está diante das novidades que ele mesmo consegue trazer à tona com seu comportamento. Mesmo quando se vive na era de extrema maquinação - ou talvez justamente por viver assim - qualquer um é capaz de permanecer maravilhado com alguma possibilidade que se revela. Heidegger demonstra no seguinte excerto que:

Costuma-se denominar a era da "civilização" aquela era do desencantamento, e esse parece, antes, andar junto somente com a completa ausência de questão. Contudo, é o contrário que se dá. Não é preciso senão que se saiba de onde vem o encantamento. Resposta: do domínio ilimitado da maquinação. [...] O enfeitiçamento por meio da técnica e de seus progressos que se ultrapassam constantemente é apenas um sinal desse encantamento, em consequência do qual tudo é impelido para o cálculo, utilização, cultivo, maneabilidade e regulação. (HEIDEGGER, 2015, p.123)

O equívoco que se revela é que as perguntas cotidianas são guiadas por um estado de enlevo provocado pela maquinação. E esse estado faz cada um procurar as respostas no cálculo, na exatidão e na tecnologia e, por isso, deixa de fora toda reflexão em torno do que significa ser, quais possibilidades de ação se apresentam em cada situação e qual verdade permanece encoberta no cotidiano. Em um sentido mais geral, o pensamento que se distancia do cálculo é aquele do qual dispensamos eficiência, uma vez que se revela como um caminho a ainda ser descoberto e percorrido. Onde o pensamento calculador descobre intenções, hipóteses e alguma prestabilidade, o pensamento meditativo pretende alcançar o desvelamento do ser e sua verdade. 
Cultivar o pensamento meditativo com zelo e dedicação requer a afetividade já inerente ao Dasein. Mesmo que essa indicação não apareça de forma literal no texto Serenidade, é possível percebê-la a partir de uma interpretação mais abrangente da obra heideggeriana. A afetividade é o existencial que nos coloca à disposição e permite que sejamos afetados pelos outros e pelos fenômenos (HEIDEGGER, 2012, p.393), enquanto meditar significa estar em conexão com as experiências vividas. A técnica e o cálculo nos dominar e impõem a si mesmos sobre nós, uma vez que são dotados de uma força própria. Com o pensamento meditativo, poderíamos contornar seus efeitos.

O exemplo de que a Gestell é comum em nossa época e ainda podemos conciliar sua presença com uma vida dedicada às reflexões amadurecidas aparece no livro Nosso amplo presente: o tempo e a cultura contemporânea (2015), de Hans Ulrich Gumbrecht. O autor mostra o exemplo comum de que o ambiente acadêmico está permeado por novas tecnologias, seja em palestras ou nas salas de aula. Sua decisão de se manter fiel a determinado modelo de ensino e pesquisa é a decisão de seguir um pensamento que o deixe mais confortável. A postura escolhida por ele expressa tanto seu desejo de não estar sempre disponível como a ideia de que muitas tecnologias surgem principalmente para cumprir um anseio estético. No caso, Gumbrecht prefere toda oportunidade de discussão presencial e troca de ideias, além do entendimento de que nesse contato é muito mais fácil sermos guiados por aquilo que realmente nos interessa ${ }^{9}$.

Somos cada vez mais privilegiados por estarmos conectados uns aos outros, porém, somos também prejudicados na medida em que nos habituamos a receber diversas informações sem qualquer esforço. Em consequência, torna-se desnecessário parar um pouco a fim de prestar mais atenção ao que está sendo dito e se esforçar para deixar o pensamento pensar. Para Heidegger, refletir significa muito mais do que adquirir conhecimento de algo. O pensamento que medita é aquele que permite ao ser-aí se desligar um pouco do excesso de novidades e das suas tentativas frequentes de controlar a natureza, o mundo, os entes e a própria existência. E isso só é possível

\footnotetext{
9 Ver especialmente o sexto capítulo desta obra, intitulado "Disponibilidade infinita: da hipercomunicação (e da terceira idade)”. (GUMBRECHT, 2015, pp.113-29)
} 
quando o Dasein cultiva uma relação com aquilo que está mais próximo, ao invés de estar atento a tudo o que vem de fora para que então seja convertido em imagens de mundo e meras representações.

A reflexão heideggeriana sobre o pensamento meditativo é amadurecida e investiga um modo de pensar que se refere aos fenômenos do mundo e conquistas humanas, visto que a meditação quer ir além de um mero vislumbre das nossas possibilidades. Meditar ou buscar um sentido é uma tentativa de se aprofundar em questões que estão submersas em um oceano de informações, experimentos e teorias, mas que na verdade estão realmente próximas e, em essência, são destituídas de modificações externas. Heidegger acredita que a simplicidade do pensamento meditativo é essa simplicidade de pensar o ser e afirma que:

O que há de estranho nesse pensar o ser é sua simplicidade. É justamente isto que nos mantém afastados dele, pois nós procuramos o pensar, visto na história universal sob o nome de 'filosofia', na figura do incomum, só acessível para os iniciados. Nós nos representamos o pensar igualmente sob o modo do conhecimento científico e seus processos de investigação. (HEIDEGGER, 2008a, p.374)

Simples aqui é distinto de pequeno e fácil, pois expressa algo tão humano que técnica alguma consegue modificar. Para esse sentido de meditação, Heidegger escolhe um deixar ser que permite ao existente humano se colocar disponível ao pensamento, ou melhor, jamais se abstrair da experiência pensante. Deixar ser é o oposto da imposição moderna e dos esforços exagerados em manipular os entes, o que nos indica que os modelos de pensamento sedimentados na era das ciências modernas e da técnica deixam de responder ao apelo ou chamado do ser. Como nos afirma Irene BorgesDuarte: "Sem sentir o ser, nenhum eco, nenhum apelo repercute." (BORGES-DUARTE, 2014, p.152)

Será que se nos guiarmos somente por um pensar tecnicista e calculador iremos fazer todas as descobertas que precisamos? E se de cada descoberta e novidade surgem outras questões, não seria justamente porque há outro modo de pensar que insiste em desvendar o ser de tudo que há? Resgatar o pensamento meditativo é nunca perder a experiência de espanto (thaumazein), pois caso contrário, o próprio pensar deixa de agir. A certeza 
absoluta, a tentativa de fundamentação e a busca automática por comprovação são insuficientes diante da inquietude que nos sustenta e nos permite romper velhos caminhos para criar os novos. O pensamento que medita nos pode libertar da ordem criada pela apropriação do saber especializado.

Heidegger proferiu e publicou Serenidade enquanto aconteciam mudanças significativas em termos de pensamento e de práxis. O século XX se modificou bastante e foi marcado por guerras frequentes, além das ascensões técnicas e tecnológicas. O filósofo alemão quis resgatar conceitos clássicos e recuperar experiências de pensar à maneira dos gregos antigos. Por isso, ele explorou o caminho em direção ao pensamento meditativo no lugar de um modelo técnico, programador e científico, isto é, do pensamento calculador.

Ser capaz de ouvir, entender, questionar, investigar e refletir é uma maneira eficaz de cada existência fugir do forte domínio do cálculo, seja quando sua ocupação no mundo consiste em filosofar ou quando passa o seu cotidiano cercado por máquinas e instrumentos desenvolvidos. Os objetos técnicos realmente parecem consistir naquilo que está mais próximo, já que eles apresentam uma utilidade que salta aos nossos olhos e seu uso se torna cada vez mais inevitável. Contudo, o que acontece em meio a esse comportamento é que nós perdemos a visão de algo fundamental e deixamos para trás a capacidade de "meditar (besinnen) sobre algo que, na nossa essência, diz respeito a cada um de nós, direta e continuamente.” (HEIDEGGER, 2002b, p.11) Ainda que o cotidiano humano se encontre estruturado pela técnica, precisamos ultrapassar a fronteira que nos separa da reflexão sobre nosso próprio ser. Resgatar o pensamento meditativo certamente é um passo fundamental que devemos ter a coragem de dar.

\section{Considerações finais}

O pensamento calculador e o pensamento meditativo são próprios ao existente humano e guardam uma implicância mútua, mas cada um desses modelos tem características particulares que muitas vezes passam despercebidas. Se olharmos para nosso cotidiano, é óbvio que estamos cercados por objetos técnicos, aparatos tecnológicos e novidades trazidas por pesquisas 
científicas. Devemos a todo instante celebrar as oportunidades criadas e as vantagens conquistadas. Mais do que nunca, precisamos valorizar as ciências e procurar nelas todo apoio necessário para a busca de desenvolvimento, segurança e bem-estar. No entanto, é igualmente essencial sabermos que o caminho para o entendimento da nossa própria existência está próximo a nós, em vez de estar na tecnologia e nas maquinações. Quando seguimos para além das determinações da técnica, das ciências experimentais e do cálculo, superamos os limites e equívocos que tais processos impõem às nossas reflexões.

Ainda precisamos lidar com a crise que o método calculador provoca nas relações humanas com os entes, a natureza e nosso campo de sentido. Certamente Heidegger não nos oferece uma solução; ele nem mesmo foi capaz de dar um exemplo prático de resolução de crises profundas quando apoiou o nacional-socialismo e, posteriormente, decidiu silenciar sobre suas escolhas. Porém, ao trazer essas questões e pensar sobre o próprio pensamento, o filósofo deixou uma possibilidade de reflexões que são urgentes para nossa atualidade. E muitos problemas que ele colocou foram antecipados por suas ideias, como uma espécie de profecia em torno do que o futuro iria trazer. Entender a diferença entre pensamento meditativo e calculador é compreender que pensar sobre o sentido - do ser de tudo que há, de nossas ações e escolhas, da verdade - se converte em uma tarefa mais elevada do que o pensamento ordenador da técnica.

Por sermos finitos, somos limitados e, em consequência, permanecemos dependentes da natureza e das ações dos outros. Dessas relações, surgem alguns impasses para os quais não temos qualquer solução imediata. A exploração irrefletida dos recursos naturais é um caso evidente de que o pensamento que calcula e explora está a destruir o planeta. No que diz respeito a viver em democracia, existem sempre questões que parecem pedir cada vez mais calma, reflexão e um diálogo sincero diante de todas as decisões que precisamos tomar. Outro impasse é quando acreditamos que temos conhecimento de todas as informações recebidas com o avanço das mídias de comunicação, mas nos deparamos com a realidade de que muitos ainda são incapazes de processar todas as notícias compartilhadas e se esquecem 
de refletir sobre a veracidade dos fatos. Portanto, conhecer o pensamento sob uma perspectiva não calculadora abre novos horizontes.

Disseminação de fake news, incêndios desproporcionais, uma pandemia que parece não ter fim ou solução, desigualdades sociais, crises econômicas, democracias fragilizadas, guerras e imigrantes desprezados por lutarem pelo direito a um solo: esses são alguns dos problemas que hoje enfrentamos. A resolução para esses e outros conflitos que vivenciamos é atravessada pela nossa capacidade de refletir com cuidado, inclusive quando necessitamos das ciências e da tecnologia para resolvê-los. Se nos mantivermos presos a uma razão instrumental e só pensarmos por meio do cálculo, nunca aprenderemos o pensamento de sentido para tomarmos decisões sensatas que realmente possam melhorar a vida sobre a terra.

Ao lado do pensamento calculador, encontramos o sujeito racional e metódico, a técnica, as ciências modernas, as tecnologias; ao lado do pensamento meditativo, encontramos a filosofia, a arte, a poesia, o cuidado, a vida fática permeada de afetos e amor ao saber. E uma meditação de sentido permite vivermos nesta era em que o exercício cotidiano de pensar algumas vezes não acompanha as inovações técnicas. A partir da captação das teorias heideggerianas, podemos elaborar os pressupostos com os quais reaprendemos a lidar com algumas questões urgentes que dizem respeito às nossas experiências atuais e, ao mesmo tempo, retornar às origens do pensamento do ser. E isso é indispensável em um mundo cada vez mais dominado pela serventia, pelo cálculo e pelas especializações.

Recebido em 14/12/2020 e aprovado em 29/01/2021

\section{Referências}

ARENDT, Hannah. A condição humana. Tradução: Roberto Raposo. $10^{\mathrm{a}}$ edição. Rio de Janeiro: Forense Universitária, 2008.

BORGES-DUARTE, Irene. Arte e técnica em Heidegger. $1^{\text {a }}$ edição. Lisboa: Documenta, 2014.

GUMBRECHT, Hans Ulrich. Nosso amplo presente: o tempo e a cultura contemporânea. Tradução: Ana Isabel Soares. São Paulo: Editora Unesp, 2015. 
HEIDEGGER, Martin. A origem da obra de arte. Tradução: Idalina Azevedo da Silva e Manuel António de Castro. São Paulo: Edições 70, 2010a.

HEIDEGGER, Martin. "A vontade de poder como conhecimento". In HEIDEGGER, Martin. Nietzsche I. Tradução: Marco Antônio Casanova. Rio de Janeiro: Forense Universitária, 2010b.

HEIDEGGER, Martin. "Carta sobre o Humanismo". In HEIDEGGER, Martin. Marcas do caminho. Tradução: Enio Paulo Giachini e Ernildo Stein. Petrópolis: Vozes, 2008a.

HEIDEGGER, Martin. "Ciência e pensamento do sentido". In HEIDEGGER, Martin. Ensaios e conferências. Tradução: Emanuel Carneiro Leão. $7^{\mathrm{a}}$ edição. Petrópolis: Vozes. Bragança Paulista: Editora Universitária São Francisco, 2006.

HEIDEGGER, Martin. Contribuições à filosofia (Do acontecimento apropriador). Tradução: Marco Antonio Casanova. $1^{a}$ edição. Rio de Janeiro: Via Verita, 2015.

HEIDEGGER, Martin. Lingua de tradição e língua técnica. Tradução: Mario Botas. Lisboa: Vegas, 1995.

HEIDEGGER, Martin. "Para discussão da serenidade". In HEIDEGGER, Martin. Serenidade. Tradução: Maria Madalena Andrade e Olga Santos. Lisboa: Instituto Piaget, 2002a.

HEIDEGGER, Martin. "Posfácio a 'O que é metafísica? "”. In HEIDEGGER, Martin. Marcas do caminho. Tradução: Enio Paulo Giachini e Ernildo Stein. Petrópolis: Vozes, $2008 \mathrm{~b}$.

HEIDEGGER, Martin. Ser e tempo. Tradução e organização: Fausto Casti1ho. Campinas: Editora Unicamp; Petrópolis: Vozes, 2012.

HEIDEGGER, Martin. "Serenidade”. In HEIDEGGER, Martin. Serenidade. Tradução: Maria Madalena Andrade e Olga Santos. Lisboa: Instituto Piaget, $2002 b$.

PEZZE, Barbara Dalle. "On the way to Gelassenheit". Minerva - An internet journal of philosophy, v.10, 2006, p. 94-122,

VOLPI, Franco. Heidegger e Aristóteles. Tradução: José Trindade dos Santos. São Paulo: Edições Loyola, 2013.

ZARADER, Marlène. Heidegger e as palavras da origem. Tradução: João Duarte. Lisboa: Instituto Piaget, 1998. 